\title{
Malnutrition in free-living elderly in rural south India: prevalence and risk factors
}

\author{
Aditya Vedantam*, Vijay Subramanian, Nicholas Vijay Rao and KR John \\ Department of Community Health, Christian Medical College, Vellore - 632002, Tamil Nadu, India
}

Submitted 14 February 2009: Accepted 27 August 2009: First published online 7 0ctober 2009

\begin{abstract}
Objective: To estimate the prevalence of malnutrition among free-living elderly in a rural population of south India.

Design: Cross-sectional study. Nutritional status was assessed using the Mini Nutritional Assessment (MNA) questionnaire, which is an eighteen-item nutritional screening instrument used in the elderly.

Setting: Kaniyambadi block, a rural development block in the state of Tamil Nadu, south India.

Subjects: Community-dwelling elderly (aged 60 years and above).

Results: As evaluated by the MNA, 14\% of the 227 subjects were malnourished and $49 \%$ were at risk of malnourishment. No significant difference was found between men and women. The majority of the elderly were living with their children, had no income and consumed three meals per day. Older age $(P<0 \cdot 001)$, decreased food intake $(P<0 \cdot 001)$ and consuming fewer meals $(P<0 \cdot 001)$ were independently associated with lower MNA scores.

Conclusions: More than $60 \%$ of the subjects had low MNA scores $(<23.5)$ indicating that deficient protein-energy intake is common among rural elderly of south India and requires more attention.
\end{abstract}



The WHO has predicted that ageing populations will present new challenges to health care. The health of the elderly will be an important issue defining the health status of a population ${ }^{(1)}$. As the number of elderly increases, so too will their health needs. Multi-morbidity associated with increasing age is common and is found to be more frequent in resource-poor countries ${ }^{(2)}$. It is therefore required that health policy addresses this subgroup of the population as well ${ }^{(1)}$.

In India, the elderly (aged 60 years and above) constitute $7 \cdot 7 \%$ of the total population of 1.04 billion and this number is increasing ${ }^{(3)}$. The majority of the elderly population lives in rural India ${ }^{(4)}$. With national health policy focusing on maternal health, child health and communicable diseases, the health status of the elderly has not been given due consideration $^{(5)}$. Since nutrition of the elderly affects immunity $^{(6)}$ and functional ability ${ }^{(7,8)}$, it is an important component of elderly care that warrants further attention.

The magnitude of malnutrition among the elderly in India is under-reported. The few studies that have been done show that more than $50 \%$ of the older population is underweight $^{(9)}$ and more than $90 \%$ has an energy intake below the recommended allowance ${ }^{(10)}$. However, only one study has been done in India using a malnutrition screening tool ${ }^{(11)}$. The use of malnutrition screening tools for community-dwelling elderly has helped to accurately identify those with low nutritional status.
There is no gold standard for estimating malnutrition among the elderly. We used the Mini Nutritional Assessment (MNA) questionnaire to estimate the magnitude of malnutrition. It is an eighteen-item validated nutritional screening instrument ${ }^{(12,13)}$ that has a sensitivity of 54-90\% when compared with a detailed nutritional assessment ${ }^{(14)}$. It is simple and non-invasive, which facilitates its use in the community ${ }^{(12)}$. It correlates well with biochemical markers of malnutrition $^{(15)}$ and is able to detect subjects at risk of malnutrition before significant changes occur in weight or serum albumin ${ }^{(12)}$. Using the MNA score subjects are categorised as malnourished $(<17)$, at risk of malnourishment $(17-23 \cdot 5)$ or well nourished $(>23 \cdot 5)$.

Studies that have been done in India and other developing countries using this questionnaire have found it to be useful and accurate ${ }^{(11,16)}$. We aimed to estimate the prevalence of malnutrition among free-living elderly in a rural south Indian setting using the MNA and to look for associated risk factors.

\section{Methods}

\section{Setting}

The study was conducted in Kaniyambadi block in the state of Tamil Nadu, south India. Kaniyambadi block is a rural development block covering an area of $127 \cdot 4 \mathrm{~km}^{2}$, 
with a population of 104832 , and is served by the Community Health Department. The elderly population (aged 60 years or more) constitutes $10.9 \%$ of the total population and $55.5 \%$ of the elderly are women (unpublished data as of 1 January 2007). The block consists of eightyseven villages and the predominant occupation is farming. Health care is provided by a combination of governmentrun primary health centres and private clinics and hospitals. There are no nursing homes that cater to the elderly in particular; all healthy elderly live at home.

\section{Sampling}

A two-stage sampling technique was used. Each village was taken as a cluster of older persons, and eight villages were selected by probability proportional to size based on the cumulative population of all villages. Subjects in each village were chosen by door-to-door visits after starting at a random household.

Subjects aged 60 years or more, who had lived in the village for the past 6 months, were included in the study. A minimum of twenty-seven subjects were taken from each village. Elderly with a known diagnosis of malignancy or those who could not stand unsupported due to debility were excluded.

\section{Assessment}

The questionnaire was administered to the participants by the authors (A.V., V.S. and N.V.R.) after verbal informed consent. The questionnaire included sociodemographic details of the participants, the complete MNA and questions regarding previous diagnosis of diabetes and hypertension, smoking, alcohol consumption, source of income and source of food. Responses were accepted from close family members of the same household if subjects could not respond accurately as a result of cognitive impairment.

\section{Statistical analyses}

The data were collected in November and December 2008. Analyses were performed using Epi-Info version 6
(Centers for Disease Control and Prevention, Atlanta, GA, USA) and SPSS Statistics17·0 (SPSS Inc., Chicago, IL, USA) software packages. Descriptive analyses were used to estimate the prevalence of malnutrition and to present other socio-economic details. To identify possible risk factors associated with poor nutritional status, univariate linear regression analysis was performed with each factor and the total MNA score. Those factors that were found to be associated with the MNA score $(P<0 \cdot 15)$ were included in the multivariate regression model to identify their independent effect. Age and sex were included in the final model. Statistical significance was set at $P<0.05$ in the final analysis.

\section{Results}

We collected data from 227 elderly subjects, with almost equal representation from each village. Median age was 68 years, and there were more women than men. Mean heights and weights were greater among men compared with the women (see Table 1).

The MNA classified $14 \%$ as malnourished and $49 \%$ at risk of malnourishment. Using BMI as the only indicator, $59 \%$ were in the normal range and $32 \%$ were found to be underweight. Mean MNA score was identical for both men and women. Poor nutritional status (MNA score $<23.5$ ) was seen almost equally between men and women (see Table 1). Sixty-four per cent of the elderly consumed three meals daily, $35 \%$ had two meals per day and consumption patterns varied with nutritional status (Fig. 1).

Smoking and alcohol consumption were seen only among men, at $15 \%$ and $6 \%$, respectively. Previous diagnosis of diabetes or hypertension was seen in $6 \%$ and $9 \%$ of the elderly, respectively. The majority of the elderly had never been screened for either condition.

Most of the elderly were living with their children (66\%), while $21 \%$ were living with another family member, often the spouse or sibling. Meals were cooked

Table 1 Sociodemographic profile, anthropometric characteristics and MNA outcomes of a sample of rural elderly from south India

\begin{tabular}{|c|c|c|c|c|c|c|}
\hline & \multicolumn{2}{|c|}{ Men ( $n$ 82) } & \multicolumn{2}{|c|}{ Women (n 145) } & \multicolumn{2}{|c|}{ Total $(n 227)$} \\
\hline & Mean or $\%$ & SD & Mean or $\%$ & SD & Mean or $\%$ & SD \\
\hline \multicolumn{7}{|l|}{ Sociodemographic profile } \\
\hline Sex $(\%)$ & $36 \cdot 1$ & - & $63 \cdot 9$ & - & $100 \cdot 0$ & - \\
\hline Age (years) & $72 \cdot 05$ & $9 \cdot 77$ & $68 \cdot 87$ & $8 \cdot 13$ & $70 \cdot 02$ & $8 \cdot 87$ \\
\hline Years of schooling & $3 \cdot 18$ & $2 \cdot 97$ & $0 \cdot 32$ & $1 \cdot 37$ & $1 \cdot 36$ & $2 \cdot 50$ \\
\hline \multicolumn{7}{|l|}{ Anthropometric characteristics } \\
\hline Height (m) & $1 \cdot 62$ & 0.06 & $1 \cdot 48$ & 0.06 & $1 \cdot 52$ & 0.09 \\
\hline Weight (kg) & $50 \cdot 94$ & $9 \cdot 27$ & $45 \cdot 78$ & $8 \cdot 98$ & $47 \cdot 64$ & $9 \cdot 36$ \\
\hline BMI $\left(\mathrm{kg} / \mathrm{m}^{2}\right)$ & $19 \cdot 51$ & $3 \cdot 32$ & $20 \cdot 95$ & $3 \cdot 70$ & $20 \cdot 43$ & $3 \cdot 62$ \\
\hline \multicolumn{7}{|l|}{ MNA outcomes } \\
\hline MNA scoret & $22 \cdot 18$ & 3.98 & $22 \cdot 17$ & 3.57 & $22 \cdot 13$ & $3 \cdot 71$ \\
\hline At risk of malnourishment (\%) & $47 \cdot 6$ & - & $50 \cdot 3$ & - & $49 \cdot 3$ & - \\
\hline Malnourished (\%) & $15 \cdot 9$ & - & $12 \cdot 4$ & - & $13 \cdot 7$ & - \\
\hline Well nourished (\%) & $36 \cdot 6$ & - & $37 \cdot 2$ & - & $37 \cdot 0$ & - \\
\hline
\end{tabular}

MNA, Mini Nutritional Assessment.

tMNA score: $<17$, malnourished; 17-23.5, at risk of malnourishment; $>23 \cdot 5$, well nourished. 


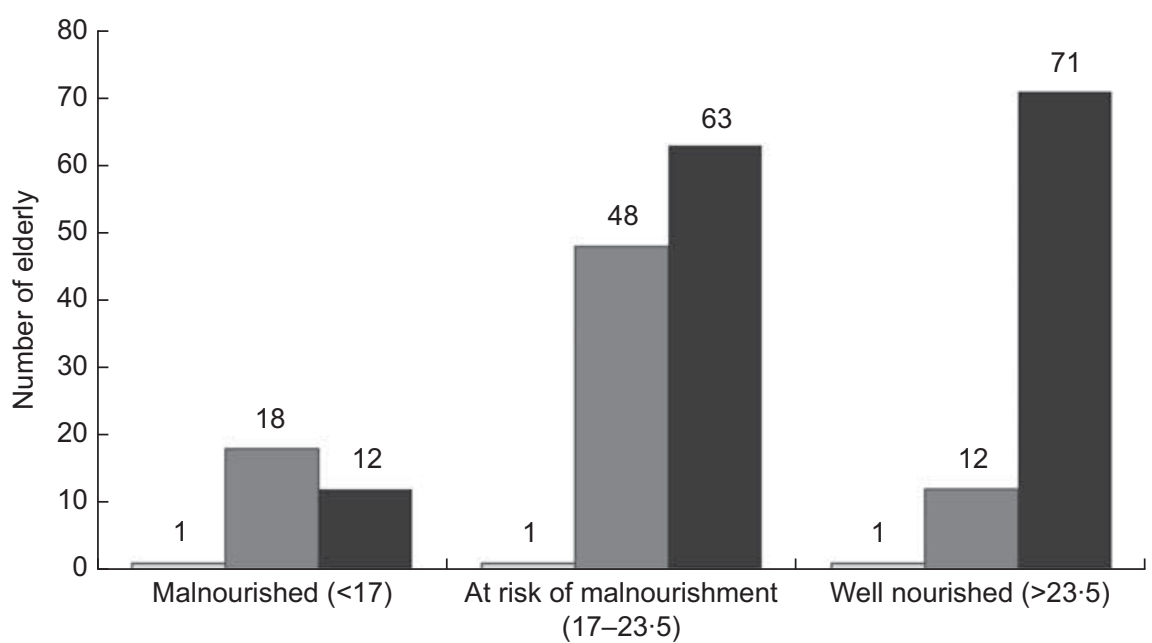

Fig. 1 Number of meals consumed per day $(\square$, one; $\square$, two; $\square$, three) in relation to nutritional status as evaluated by the Mini Nutritional Assessment (MNA), in a sample of rural elderly from south India

Table 2 Factors associated with MNA scores in univariate and multivariate linear regression analyses in a sample of rural elderly from south India

\begin{tabular}{|c|c|c|c|}
\hline \multirow[b]{2}{*}{ Variable } & \multirow{2}{*}{$\frac{\text { Univariate analysis }}{P \text { value }}$} & \multicolumn{2}{|c|}{ Multivariate regression modelt } \\
\hline & & Standardized $\beta$ & $P$ value \\
\hline Age & $<0.001^{*}$ & -0.309 & $<0.001^{\star *}$ \\
\hline Sex & 0.897 & 0.003 & 0.955 \\
\hline Years of schooling & $0.005^{\star}$ & 0.064 & 0.250 \\
\hline Number of mealsł & $<0.001^{*}$ & 0.302 & $<0.001^{\star \star}$ \\
\hline Decreased food intake & $<0.001^{*}$ & -0.380 & $<0.001^{\star *}$ \\
\hline Earning§ & $<0.001^{*}$ & 0.061 & 0.298 \\
\hline Pension§̧ & 0.976 & & \\
\hline No income & $0.002^{*}$ & -0.085 & $0 \cdot 127$ \\
\hline Living alone & $0.095^{\star}$ & -0.028 & 0.614 \\
\hline Living with children & 0.607 & & \\
\hline
\end{tabular}

MNA, Mini Nutritional Assessment.

${ }^{\star} P<0.15$ (level of significance set for factors to be included in multivariate model), ${ }^{\star \star} P<0 \cdot 05$.

tMultivariate regression model using stepwise approach, adjusted for age and sex.

$\ddagger$ Number of meals consumed per day.

§Only source of income.

by the elderly themselves (51\%) or their children (46\%). The remaining 3\% obtained their food from neighbours or siblings living in other households.

Forty-nine per cent of the subjects had no income, while $29 \%$ received a pension (military or governmentsponsored) and $22 \%$ were earning (daily wages or monthly salary). Twenty per cent of the elderly received a government-sponsored old-age pension ( $400 \mathrm{Rs} /$ month; US $\$ 1=48$ Rs during the study period). Retired military personnel or their spouses $(8.3 \%)$ received a military pension (2000-5000 Rs/month). One hundred and ninety-nine of the total 227 subjects were able to report the household expenditure on food. Mean per capita daily expenditure was 16.67 Rs.

Possible factors associated with MNA scores $(P<0 \cdot 15)$ identified by univariate linear regression included age, years of schooling, number of meals per day, decline in food intake, earning a living, no income and living alone (see Table 2). Multivariate regression analysis, adjusted for age and sex, was performed with these factors using a stepwise approach. This showed that the independent factors associated with lower MNA score were increasing age $(\beta=-0.312, \quad P<0.001)$, decline in food intake $(\beta=-0 \cdot 380, \quad P<0 \cdot 001)$ and fewer meals $(\beta=0 \cdot 302$, $P<0.001)$. Factors such as living alone, absence of income and years of schooling were not found to be significantly associated with lower MNA score.

\section{Discussion}

Previous studies in south India have shown a high prevalence of malnutrition among the elderly ${ }^{(9,10)}$. The only study conducted using the MNA questionnaire in India was done in western Rajasthan, and showed a higher prevalence of malnourishment and risk of malnourishment among the rural elderly compared with the urban elderly (11\% and $62 \%$ v. $2 \%$ and $36 \%$, respectively) ${ }^{(11)}$. 
We found a similar prevalence of malnutrition among our population compared with the rural population of western Rajasthan (14\% v. 11\%). However, we had a smaller proportion of the population at risk of malnutrition ( $49 \%$ v. $62 \%)$. Compared with the results from a large study among rural elderly of Bangladesh ${ }^{(16)}$, our population shows lower rates of malnutrition.

In comparison to studies among community-dwelling or home-care elderly in developed countries, our study showed a similar prevalence of risk of malnutrition but higher rates of overt malnutrition ${ }^{(17-20)}$. A large study done in Spain showed lower rates of malnutrition and risk of malnutrition $\left(4 \cdot 3 \%\right.$ and $25 \cdot 4 \%$, respectively) ${ }^{(21)}$ than our study.

The MNA uses a higher BMI cut-off $\left(19 \mathrm{~kg} / \mathrm{m}^{2}\right)$ than that recommended by the WHO $\left(18.5 \mathrm{~kg} / \mathrm{m}^{2}\right)$. Analysis of the MNA data with this lower cut-off showed a decrease in the prevalence of malnutrition and risk of malnutrition (to $11.9 \%$ and $48.9 \%$, respectively) as compared with the original MNA ( $14 \%$ and $49 \%$, respectively). Although we chose to use the MNA without any modifications, the cutoff values for BMI and malnutrition differ between populations and hence our results should be interpreted accordingly. Other studies have modified the MNA for use in their respective populations ${ }^{(16,22)}$, however, without validation of the same. Previous studies in south India have shown a high prevalence of undernutrition among the elderly ${ }^{(9,10)}$, suggesting that our estimate appears close to the true value. However, we feel that the use of a modified MNA specific for our population would give more accurate results.

Our results showed more elderly at risk of malnourishment than actually malnourished. This finding has been seen among community-dwelling elderly from India and other parts of the world ${ }^{(11,18,20,21,23,24)}$. This is primarily due to the fact that the MNA is better at identifying those at risk of malnourishment among healthy elderly in the community ${ }^{(12)}$. More importantly, this emphasises the fact that among the elderly, there is high prevalence of deficient protein-energy intake without obvious malnutrition.

Older age was associated with lower MNA scores in our population. This finding has been shown in some previous studies $^{(16,21)}$, while others have shown that age has no effect on nutritional status ${ }^{(17,24)}$. We observed that the older subjects were less active and often reported reduced appetite and decreased food intake. It is apparent that increased focus on nutritional status is required as the age of the elderly increases.

Our analysis showed that lower MNA scores were associated with those subjects who had fewer than three meals per day. A similar finding was reported in Bangladesh, where most of the elderly who were malnourished or at risk of malnourishment consumed only two meals daily ${ }^{(16)}$. Other studies involving communitydwelling elderly have shown that chewing problems and difficulty preparing or eating full meals contribute to poor nutritional status ${ }^{(11,17,24)}$. Thirty-eight per cent of elderly in our study reported moderate to severe decline in food intake. The majority of these subjects indicated that decreased appetite was the cause for low food intake. Decreased appetite can be attributed to physiological changes during ageing as well as medical conditions in the elderly ${ }^{(25,26)}$. Previous studies have linked depression and malnutrition among free-living elderly ${ }^{(24,27)}$. Geriatric depression in Kaniyambadi block was found to be associated with decreased nourishment ${ }^{(28)}$ and it may be an important factor affecting food intake in our population. In our population, lunch was the major meal of the day and dinner was often omitted. A previous study in a similar population had shown that insufficient income and inadequate knowledge of nutrient requirements were possible factors associated with low energy intake ${ }^{(10)}$. We observed that economic pressure did influence dietary patterns to a large extent, but we did not assess knowledge or attitudes of the elderly towards nutrition.

Since our study was aimed primarily at studying the prevalence of malnutrition, identifying risk factors in greater detail would have benefited from a larger sample size. In rural India, elderly subjects often do not know their own age and so an estimate based on age at marriage, age of their children or age recorded on government-issued ration cards is used. This was not a major problem in our study but may be a significant point for future researchers targeting particular age groups among the elderly. Only two subjects could not participate in the study because they were unable to stand and this did not affect our results. However, exclusion of a sizeable number of debilitated subjects in future studies can give an incomplete picture of the nutritional status in a community, as disease is an important predictor of malnutrition among free-living elderly ${ }^{(16)}$. We also found that subjects had difficulty stating their daily food expenditure primarily because rice, which constitutes the largest part of any meal, is bought once monthly, while vegetables and pulses were bought once or twice weekly. Also, in households where elderly lived with their children, the member of the household with knowledge of the finances was often not available for response. A detailed analysis of the diet, which was lacking in our study, would have given a more complete picture of the nutritional status. Future research in this area should include diet analysis, economics of nutrition, feasibility and effects of nutritional intervention programmes.

In conclusion, we present the first study in south India that uses the MNA to assess malnutrition in the elderly. Our results have shown that more than $60 \%$ of the rural elderly had low MNA scores. Low MNA scores were associated with older age, decreased food intake and consuming fewer meals. Considering the high prevalence of poor nutritional status in the elderly, more focus on diet and possible nutritional interventions is required. 


\section{Acknowledgements}

No funding was obtained for the present study. There are no conflicts of interest. A.V., V.S., and N.V.R. were involved in data collection and analysis. A.V., V.S. and K.R.J. wrote the manuscript and all authors read and approved the final version. We would like to thank Rajiv Sarkar and Pearline Suganthy, Christian Medical College, Vellore, for assistance with statistical analysis. We are also grateful to the people of Kaniyambadi block for their cooperation and willingness to participate.

\section{References}

1. World Health Organization (2008) The World Health Report 2008: Primary health care now more than ever. http:// www.who.int/whr/2008/en/ (accessed January 2009).

2. Joshi K, Kumar R \& Avasthi A (2003) Morbidity profile and its relationship with disability and psychological distress among elderly people in Northern India. Int J Epidemiol 32, 978-987.

3. World Health Organization (2004) The World Health Report 2004. http://www.who.int/whr/2004/annex/country/ind/ en/index.html (accessed January 2009).

4. Bhat AK \& Dhruvarajan R (2001) Ageing in India: drifting intergenerational relations, challenges and options. Ageing Soc 21, 621-640.

5. Ministry of Health and Family Welfare (2002) National Health Policy - 2002. http://mohfw.nic.in/np2002.htm (accessed January 2009).

6. Lesourd B (2004) Nutrition: a major factor influencing immunity in the elderly. J Nutr Health Aging 8, 28-37.

7. Stuck AE, Walthert JM, Nikolaus T et al. (1999) Risk factors for functional status decline in community-living elderly people: a systematic literature review. Soc Sci Med 48, 445-469.

8. Galanos AN, Pieper CF, Cornoni-Huntley JC et al. (1994) Nutrition and function: is there a relationship between body mass index and the functional capabilities of community-dwelling elderly? J Am Geriatr Soc 42, 368-373.

9. Natarajan VS, Shanthi R, Krishnaswamy B et al. (1995) High prevalence of nutritional disorders and nutrient deficits in elderly people in a rural community in Tamil Nadu, India. J H K Geriatr Soc 6, 40-43.

10. Natarajan VS, Shanthi R, Sivashanmugam et al. (1993) Assessment of nutrient intake and associated factors in an Indian elderly population. Age Ageing 22, 103-108.

11. Baweja S, Agarwal H, Mathur A et al. (2008) Assessment of nutritional status and related risk factors in community dwelling elderly in western Rajasthan. J Indian Acad Geriatr 4, 5-13.

12. Guigoz Y, Lauque S \& Vellas BJ (2002) Identifying the elderly at risk for malnutrition. The Mini Nutritional Assessment. Clin Geriatr Med 18, 737-757.
13. Guigoz Y, Vellas B \& Garry PJ (1996) Assessing the nutritional status of the elderly: the Mini Nutritional Assessment as part of the geriatric evaluation. Nutr Rev 54, 59-65.

14. Guigoz Y (2006) The Mini Nutritional Assessment (MNA ${ }^{\circledR}$ ) review of the literature - what does it tell us? J Nutr Health Aging 10, 466-485.

15. Vellas B, Guigoz Y, Baumgartner M et al. (2000) Relationships between nutritional markers and the Mini-Nutritional Assessment in 155 older persons. J Am Geriatr Soc 48, 1300-1309.

16. Kabir ZN, Ferdous $\mathrm{T}$, Cederholm $\mathrm{T}$ et al. (2006) Mini Nutritional Assessment of rural elderly people in Bangladesh: the impact of demographic, socio-economic and health factors. Public Health Nutr 9, 968-974.

17. Soini H, Routasalo P \& Lagström H (2004) Characteristics of the Mini-Nutritional Assessment in elderly home-care patients. Eur J Clin Nutr 58, 64-70.

18. de Groot LCPGM, Beck AM, Schroll M et al. (1998) Evaluating the DETERMINE Your Nutritional Health Checklist and the Mini Nutritional Assessment as tools to identify nutritional problems in elderly Europeans. Eur J Clin Nutr 52, 877-883.

19. Izawa S, Kuzuya M, Okada K et al. (2006) The nutritional status of frail elderly with care needs according to the mininutritional assessment. Clin Nutr 25, 962-967.

20. Saletti A, Johansson L, Yifter-Lindgren E et al. (2005) Nutritional status and a 3-year follow-up in elderly receiving support at home. Gerontology 51, 192-198.

21. Cuervo M, García A, Ansorena D et al. (2009) Nutritional assessment interpretation on 22,007 Spanish communityswelling elders through the Mini Nutritional Assessment test. Public Health Nutr 12, 82-90.

22. Kuzuya M, Kanda S, Koike T et al. (2005) Evaluation of Mini-Nutritional Assessment for Japanese frail elderly. Nutrition 21, 498-503.

23. Beck AM, Ovesen L \& Osler M (1999) The 'Mini Nutritional Assessment' (MNA) and the 'Determine Your Nutritional Health' Checklist (NSI Checklist) as predictors of morbidity and mortality in an elderly Danish population. BrJ Nutr 81, $31-36$.

24. Iizaka S, Tadaka E \& Sanada H (2008) Comprehensive assessment of nutritional status and associated factors in the healthy, community-dwelling elderly. Geriatr Gerontol Int 8, 24-31.

25. Donini LM, Savina C \& Cannella C (2003) Eating habits and appetite control in the elderly: the anorexia of aging. Int Psychogeriatr 15, 73-87.

26. Morley JE (2001) Decreased food intake with ageing. J Gerontol A Biol Sci Med Sci 56, 81-88.

27. Cabrera MA, Mesas AE, Garcia AR et al. (2007) Malnutrition and depression among community-dwelling elderly people. J Am Med Dir Assoc 8, 582-584.

28. Rajkumar AP, Thangadurai P, Senthilkumar P et al. (2009) Nature, prevalence and factors associated with depression among the elderly in a rural south Indian community. Int Psychogeriatr 21, 372-378. 